\title{
Gas gangrene abscess of the brain
}

\author{
P. R. R. CLARKE \\ From the Neurosurgical Unit, Middlesbrough General Hospital
}

Reviews of the literature dealing with gas gangrene abscess of the brain have been carried out by Russell and Taylor (1963), and by Morello and Bettinazzi (1966). Acceptance of a case as being one of gas gangrene abscess requires both the demonstration of gas in an abscess cavity and the identification of an organism which is capable of gas production. The case here described is the nineteenth to be reported and the eleventh to come from civilian practice. It is the third to result from infection in the middle ear cavity, the two previous accounts of this unusual complication of otitis media being by Heineman and Braude (1963) and by Morello and Bettinazzi (1966). Although the abscess ruptured into the ventricular system the patient made a good recovery.

\section{CASE REPORT}

A miner aged 51, who had suffered from bilateral otitis media since childhood, developed mental confusion and drowsiness during the last week of October 1966. For a week previously it had been noted that discharge from the right ear was profuse. He was admitted to his local hospital where a right endaural mastoidectomy was performed on 28 October. After operation his condition continued to deteriorate and he was transferred to the neurosurgical unit on 31 October. Examination revealed a man who moved all limbs in response to painful stimuli but who was too drowsy to cooperate or to reply to simple questions. The temperature was $97^{\circ} \mathrm{F}$ and the pulse rate $80 / \mathrm{min}$. Neck stiffness was marked and Kernig's sign was present. The optic fundi were normal. A left hemiparesis was obvious, tendon reflexes in the left leg were increased, and the left plantar response was extensor in type. Echoencephalography showed that the mid-line structures were displaced $3.5 \mathrm{~mm}$ to the left.

Under local analgesia a right temporal burr-hole was made and the dura mater was opened. A cannula was inserted into the bulging brain and $2 \mathrm{ml}$. of thick, foulsmelling pus were aspirated. A mixture of penicillin $10,000 \mathrm{u}$., streptomycin $50 \mathrm{mg}$, and micropaque barium sulphate (Steripaque) $1 \mathrm{ml}$. was injected into the abscess cavity and the scalp wound was then sutured. Systemic treatment with penicillin $1 \mathrm{Mu}$. four-hourly and streptomycin $1 \mathrm{~g}$ 12-hourly was started. Examination of the pus showed the presence of Proteus mirabilis and an organism of the fusiformis group. Both these were sensi- tive to tetracycline and streptomycin but the latter was insensitive to penicillin. On 4 November the antibiotic treatment was changed to tetracycline $500 \mathrm{mg}$ six-hourly and streptomycin $0.5 \mathrm{~g}$ 12-hourly. Radiographs showed Steripaque in a right temporal lobe cavity and also in the ventricular system (Fig. 1). The patient's condition improved steadily, but he remained very drowsy and incontinent of urine. On 11 November a further radiological investigation was carried out and this showed gas in the right lateral and third ventricles (Fig. 2). The abscess was aspirated for the second time and on this occasion Clostridium welchii was found in the pus. Because of the presence of Clostridium welchii the antibiotic treatment was changed to penicillin $1 \mathrm{Mu}$. twohourly, streptomycin $0.5 \mathrm{~g}$ 12-hourly and injection of tetracycline $100 \mathrm{mg}$ six-hourly. Gas gangrene antitoxin, $150,000 \mathrm{u}$. was given by intramuscular injection. On 14 November the patient was able to carry on a simple conversation but was still very drowsy and the left hemiparesis persisted. Radiological examination showed less gas in the ventricular system. On 15 November, because of slow progress, it was decided to administer antibiotics by the intraventricular route. Under general anaesthesia the right lateral ventricle was tapped through a posterior parietal burr hole. The brain was bulging and, when the large ventricle was entered by the cannula, yellow turbid fluid escaped under considerable pressure. Penicillin $5,000 \mathrm{u}$. and streptomycin $50 \mathrm{mg}$ were injected into the ventricle. The ventricular fluid was found to consist of frank pus. It was sterile on culture. Five millitres of pus were aspirated from the abscess and penicillin $5,000 \mathrm{u}$. with streptomycin $50 \mathrm{mg}$ were injected into it. The pus was sterile on culture. On four further occasions during the next six days the right lateral ventricle was tapped and penicillin with streptomycin were injected into it. From the day following the first intraventricular injection of antibiotics the patient's condition progressively improved. The administration of streptomycin was stopped on the 30 November, a total of $34 \mathrm{~g}$ of this drug having been given. Tetracycline and penicillin were given until 7 December. On 23 December the patient was allowed to go home, after having been in hospital for a total of 56 days. At that time he was perfectly rational, continent of urine, and able to walk with support. Radiographs showed satisfactory shrinkage of the abscess. On 4 January 1967 the patient's wife said that she considered her husband to be as well mentally as he had been before his illness. He was noted to have a residual left hemiparesis but to be walking much better with a little support. On 9 February a left radical mastoidectomy was performed 


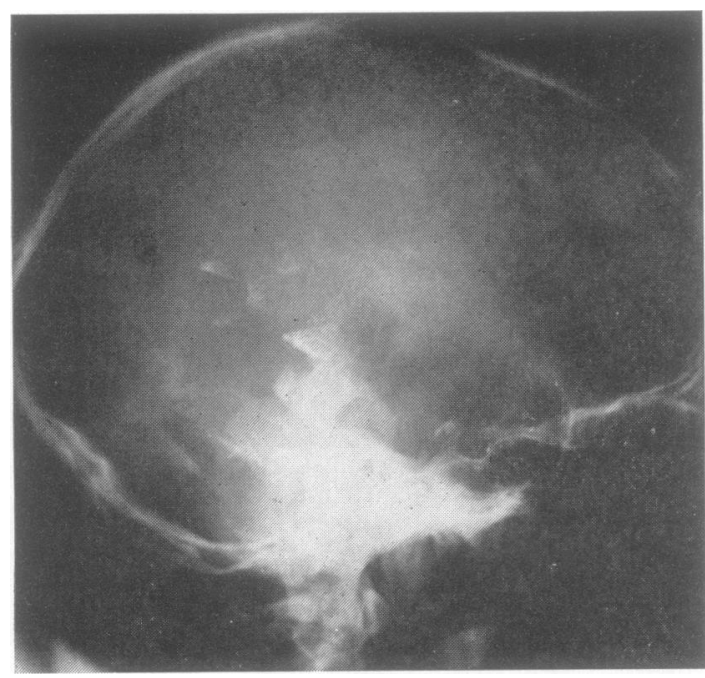

FIG. 1. Lateral radiograph showing Steripaque in the abscess cavity and ventricular system.

by Mr. Martin Horowitz. Cholesteatoma and granulation tissue were removed. In August 1967 the patient was walking distances of up to one mile without assistance and was well, apart from deafness and some restriction of movement in the left shoulder joint.

\section{DISCUSSION}

In this case aspiration of the abscess, injection of antibiotics into the abscess and the ventricles, together with the systemic antibiotic therapy, produced cure. It was noted that the patient's condition rapidly changed for the better after the first injection of penicillin and streptomycin into the ventricles. It is felt that this form of treatment is of great value in cases of cerebral abscess with infection of the ventricular fluid.The small capacity of the abscess $(2 \mathrm{ml}$.) was explained by the fact of rupture into the right lateral ventricle clearly shown by the Steripaque pyograms. In the author's previous experience rupture of a brain abscess into the ventricular system has invariably been fatal. The gratifying outcome in this case seems to bear out the view of Cairns,

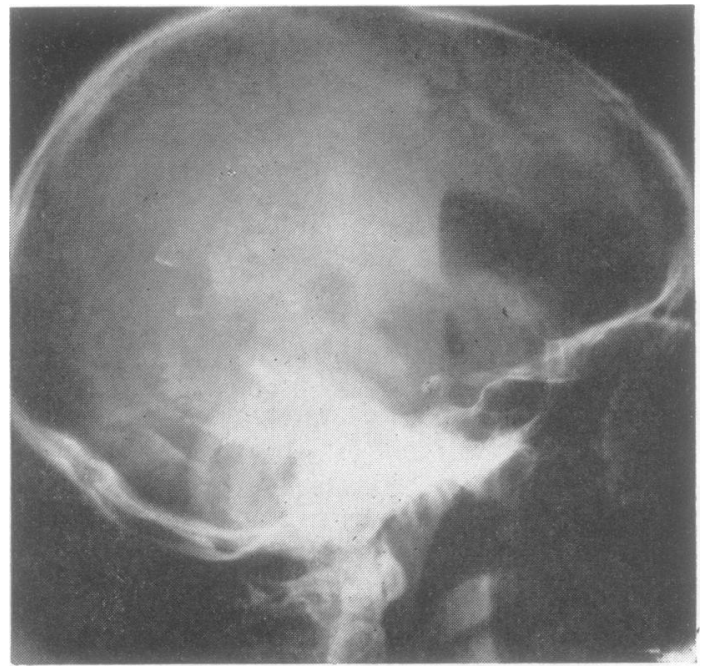

FIG. 2. Radiograph showing gas in the lateral and third ventricles.

Calvert, Daniel, and Northcroft (1947), that gas bacillus brain infections are relatively benign.

\section{SUMMARY}

A case of otogenic brain abscess, with gas formatiog by $\mathrm{Cl}$. welchii, and rupture into a lateral ventricle is described. Recovery followed aspiration of the abscess and the administration of antibiotics locall into the abscess and lateral ventricle, as well systemically.

It is a pleasure to acknowledge Mr. Martin Horowitz's advice and practical assistance in the management of the ear infections.

\section{REFERENCES}

Cairns, H., Calvert, C. A., Daniel, P., and Northcroft, G. B. (1947). Complications of head wounds, with especial reference to infection. Brit. J. Surg., War Surgery Supplement No. 1 , 198-243.

Heineman, H. S., and Braude, A. I. (1963). Anaerobic infection of the brain. Observations on eighteen consecutive cases of brain abscess. Amer. J. Med., 35, 682-697.

Morello, A., and Bettinazzi, N. (1966). Brain abscess due to gas bacillus infection. J. Neurosurg., 24, 752-754.

Russell, J. A., and Taylor, J. C. (1963). Circumscribed gas-gangrene abscess of the brain. Case report together with an account of the literature. Brit. J. Surg., 50, 434-437. 